\title{
Literature Review for the Management of Isolated Internal Mammary Artery Injury and a Case Managed by Mini-Thoracotomy
}

\author{
Mohammad Miah', Mauin Uddin'2, Jalal Bin Saeid1', Syed Al Nahian³, Anwar Karim1, \\ Ahmed Ashoub ${ }^{1}$
}

${ }^{1}$ Queen Elizabeth Hospital Birmingham (QEHB), Birmingham, UK

${ }^{2}$ New Cross Hospital, Wolverhampton, UK

${ }^{3}$ Liverpool Heart and Chest Hospital, Liverpool, UK

Email: Mohammad.miah1@nhs.net

How to cite this paper: Miah, M., Uddin, M., Saeid, J.B., Al Nahian, S., Karim, A. and Ashoub, A. (2019) Literature Review for the Management of Isolated Internal Mammary Artery Injury and a Case Managed by Mini-Thoracotomy. World Journal of Cardiovascular Surgery, 9, 83-88.

https://doi.org/10.4236/wjcs.2019.98010

Received: June 6, 2019

Accepted: August 19, 2019

Published: August 22, 2019

Copyright $\odot 2019$ by author(s) and Scientific Research Publishing Inc. This work is licensed under the Creative Commons Attribution International License (CC BY 4.0).

http://creativecommons.org/licenses/by/4.0/

\section{c) (i) Open Access}

\begin{abstract}
Penetrating injuries to anterior chest may result in life-threatening complications such as massive haemothorax, as a result of injury to the internal mammary artery. Isolated internal mammary injury is a very rare cause of massive haemothorax and associated with high mortality. We are presenting this 32-year-old gentleman who sustained a thoracic stab wound and had an emergency right anterior mini-thoracotomy by extending the stab wound rather than standard thoracotomy or sternotomy. This case of isolated penetrating IMA injury managed with mini-thoracotomy is the only documented case so far. We are publishing this case report with patient's both written and informed consent and institutional approval. This potentially life-threating injury can be managed by mini-thoracotomy with enhanced recovery; however, it is case specific and needs proper judgement.
\end{abstract}

\section{Keywords}

Internal Mammary Artery (IMA), Mini-Thoracotomy, Massive

Haemothorax, External Cardiac Tamponade

\section{Literature Review}

Isolated injury to internal mammary artery is rarely reported in literature. It can be a consequence of penetrating or blunt trauma, both of infrequent in occurrence but still with serious outcome. Others have reported internal mammary injury that had happened from central line insertion. The presentation of inter- 
nal mammary injury differs from the fairly stable patient that can be considered in a timely manner to recognize the source of hemothorax, to a late presentation of massive hemothorax that mandate thoracotomy. Many treatment choices have been described so far, but all rest on the hemodynamic stability of the injured patients. If a patient is not in cardiac arrest, relieve of hemothorax through a chest tube is the first line of intervention. Although there is not adequate experience stated with this injury, chest tube insertion would release tension hemothorax. If on the other hand insertion of chest tube is not adequate enough or if patient presents with witnessed cardiac arrest of fewer than 10 minutes, then emergency department resuscitative thoracotomy should be undertaken, if there is a surgeon in the institution providing the care. The injured internal mammary might be treated based on the clinical situation. This management comprises angioembolization or open operation and ligation of the injured vessel.

Massive tension haemothorax resulting from penetrating internal mammary artery injury, managed with anterior mini-thoracotomy with uneventful recovery, as in our case, has not been reported yet. Nevertheless, isolated injury to IMA is infrequently reported in literature. It can be a result of penetrating or blunt trauma but still with serious consequences. Including the current patient, there are only seven reported cases of isolated IMA injury, with successful recovery after surgery. According to the cumulative data, the mean age of the patients was 38 years (range 21 - 55 years). All of the patients were males. The predominant mechanism of injury was penetrating injury with a penetrating-to-blunt trauma ratio of $6: 1$. Four (57\%) of the 7 patients presented were haemodynamically unstable (Table 1 ). Among the penetrating injuries, four patients developed early massive haemothorax and became haemodynamically unstable. The other two patients who were haemodynamically stable, developed delayed pericardial tamponade, and one also developed delayed massive haemothorax. The patient with blunt trauma was haemodynamically stable; however, he developed delayed external tamponade. Two of the penetrating injuries

Table 1. Summary of the Review from the literatures of isolated internal mammary artery injuries.

\begin{tabular}{|c|c|c|c|c|c|c|c|c|}
\hline Study & Age in year & Sex & $\begin{array}{l}\text { Mechanism } \\
\text { of injury }\end{array}$ & Hemodyna-mic & $\begin{array}{l}\text { Pericardial } \\
\text { Tamponade }\end{array}$ & $\begin{array}{c}\text { Massive } \\
\text { Haemothorax }\end{array}$ & Surgery & Outcome \\
\hline Curley et al. (1987) [1] & 41 & Male & Penetrating & Unstable & Early & Early & Sternotomy & Alive \\
\hline Vinces (2005) [2] & 21 & Male & Penetrating & Stable & Delayed & Delayed & Thoracotomy & Alive \\
\hline Holt et al. (2005) [3] & 26 & Male & Penetrating & Stable & Delayed & No & Sternotomy & Alive \\
\hline Irgau et al. (1995) [4] & 53 & Male & Blunt & Stable & Delayed external & No & Sternotomy & Alive \\
\hline Hassani et al. (2012) [5] & 32 & Male & Penetrating & Unstable & Early external & Early & Thoracotomy & Alive \\
\hline Islam S et al. (2014) [6] & 55 & Male & Penetrating & Unstable & Early external & Early & Thoracotomy & Alive \\
\hline Current case & 32 & Male & Penetrating & Unstable & Early external & Early & $\begin{array}{c}\text { Anterior } \\
\text { mini-thoracotomy } \\
\text { via wound } \\
\text { exploration }\end{array}$ & Alive \\
\hline
\end{tabular}


patients underwent median sternotomy and the next two underwent anterolateral or anterior [current case] thoracotomy. The lone blunt injury patient presented with delayed pericardial tamponade and was hemodynamically stable with no massive haemothorax and underwent median sternotomy. Our patient presented in a haemo-dynamically unstable condition with single stab wound in the chest with massive tension haemothorax with early external cardiac tamponade. He underwent anterior mini-thoracotomy via wound exploration with ligation of IMA followed by an excellent full recovery.

\section{Case Presentation}

This 32-year-old gentleman was admitted to Queen Elizabeth Hospital Birmingham as an emergency after sustaining a stab wound to the right upper chest. He was in hypovolemic shock with a blood pressure of $80 / 45 \mathrm{~mm} \mathrm{Hg}$ and pulse rate of 120 beats per minute. Stab wound was noted, in his right anterior chest wall medial to mid-clavicular line and in right parasternal area at $3 \mathrm{rd}$ inter costal space measuring about $3 \mathrm{~cm} \times 1 \mathrm{~cm}$ with intra thoracic extension. A right sided 36-French chest tube was placed which immediately drained $2000 \mathrm{mls}$ of blood moment after arrival in emergency department. Patient was resuscitated with warm crystalloid as well as 3 units of group specific blood. The CT scan of chest later on showed a large right sided haemothorax with no great vessel injury. However, extravasation of contrast was not noticed through the right IMA (Figure 1). He was consented for mini thoracotomy and wound exploration with a possibility of conversion to standard thoracotomy or sternotomy if necessary. Right anterior mini-thoracotomy extending the wound at 3rd inter costal space was performed. Active arterial bleeding from the right IMA and alaceration of $1 \mathrm{~cm}$ depthon the upper lobe of the right lung were identified.

Moderate haemothorax with clot was found. Bleeding from the right IMA was controlled proximally with Ethicon 5 stitch and LIGACLIP. More LIGACLIPs were applied to distal end. The laceration in the lung was repaired by Vicryl 2/0. Haemothorax and clot were evacuated and generous saline wash was done. After haemostasis the apical drain was kept in place and a basal drain was inserted. Wound was closed in layers and local anaesthetic agent to the wound site was applied. Postoperative X-ray was satisfactory (Figure 2).

Understandably, the patient had been traumatised by the incident and was seen by the psychiatric team prior to discharge. They had deemed him fit for discharge from a psychiatric perspective. On discharge, he was independently mobile, wounds were clean and dry. He was seen in outpatient follow up clinic with no complications (Figure 3) and went back to his normal life.

\section{Discussion}

Isolated injury to IMA is a confusing problem, which is hard to diagnose on time. So far, successful diagnosis and effective treatment are two of the most challenging tasks in the management of IMA injury. The table illustrates that the 


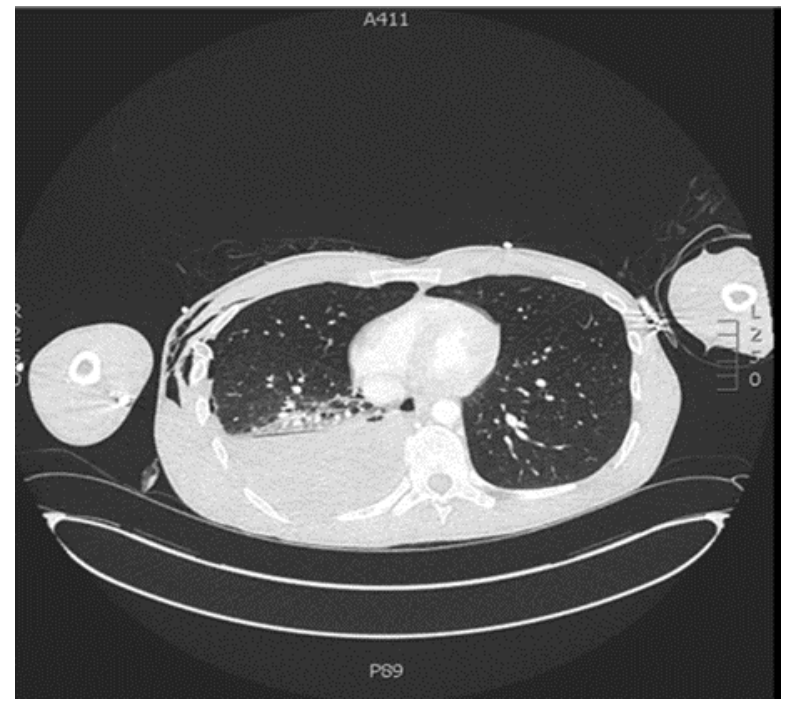

Figure 1. Preoperative CT scan showing large right sided haemothorax.

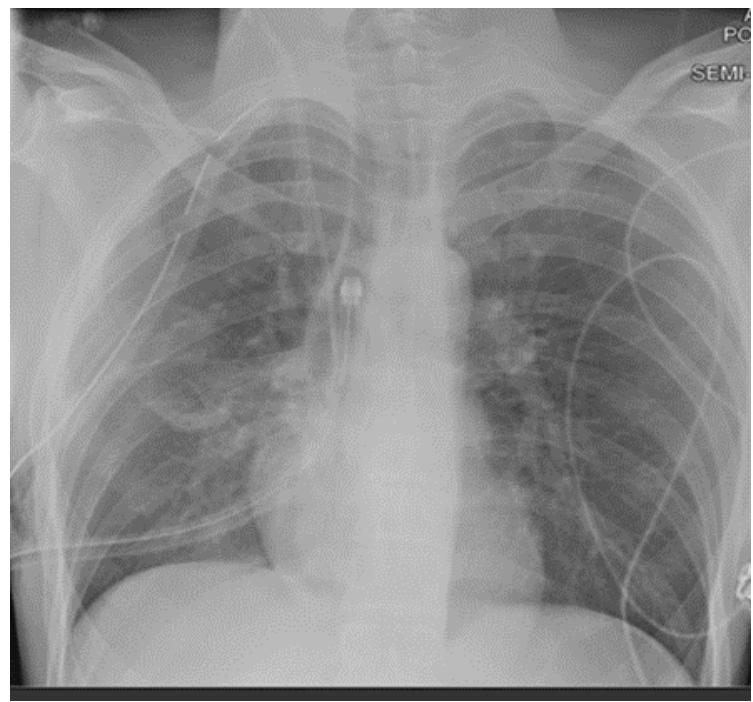

Figure 2. Postoperative X-ray showing no haemothorax with right sided chest drain in situ.

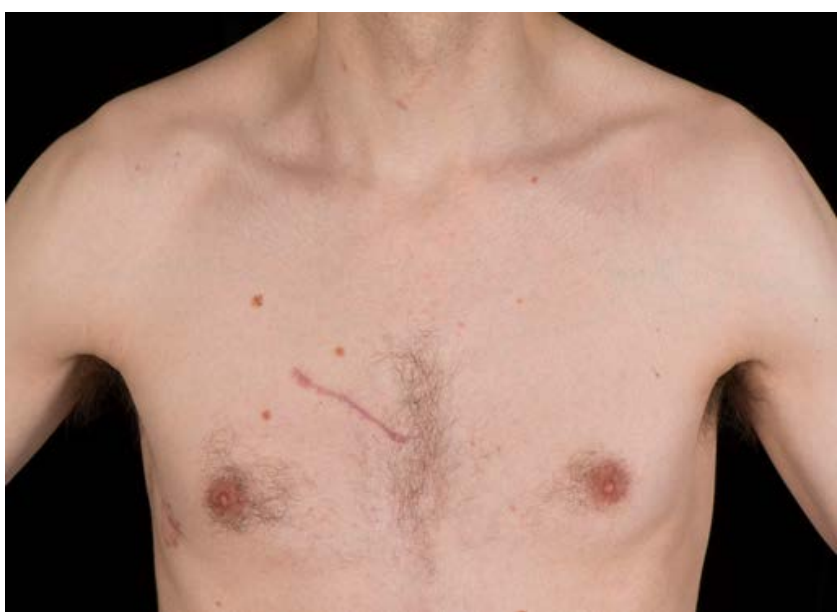

Figure 3. Mini-thoracotomy scar after 4 weeks in the follow up clinic. 
presentation of internal mammary artery injury varies from relatively stable patient, to an unstable patient with massive haemothorax. Once an IMA injury goes undetected, the consequences are grave because of the manifestation of lethal shock in $45 \%$ of patients with IMA injury. Thus, it is vital to consider the occurrence, nature of bleeding, and treatment in IMA injury.

For IMA injuries, these are more reported to be in males, and affect mainly the left side. The leading reasons for IMA injuries are road traffic accidents. Chen et al. (2001) described that $85 \%$ of the injured branch vessels directly originated from the aortic arch. Therefore, the greater occurrence of the left IMA may be associated with the anatomic structure being nearer to the aortic arch.

The IMA rises from the concavity of the first part of the subclavian artery and instantly passes downwards, forwards and medially, lying upon the pleura in the upper intercostal spaces up to the third costal cartilage; after this, it continues in front of the transversus thoracis muscle to finish in the sixth intercostal space by dividing into the superior epigastric and musculophrenic arteries. Injury of the IMA produces a hematoma restricted by the parietal pleura and/or the transversus thoracis muscle. In addition, if the parietal pleura remain intact blood cannot pass into the pleural cavity. Thus, different parts and degrees of IMA injury, adjacent vein injury, and the integrity of the pleura, determine differences in bleeding modality.

Even though IMA transection may sometimes retract and achieve momentary hemostasis during periods of hypotension and arterial spasm, renewed bleeding can ensue once the patient is resuscitated. The IMA blood flow is approximately $150 \mathrm{ml} / \mathrm{min}$, which can result in a life-threatening hemorrhage within a few $\mathrm{mi}$ nutes (Ritter and Chang, 1995). Early thoracotomy is vital for salvaging patients having chest-wall vascular injury.

Active extravasation of contrast material might be noticed in trauma patients who are physiologically stable enough to undergo contrast-enhanced computed tomography (CT) of the thorax, unless IMA is in transient spasm. CT precisely shows the anatomic location of bleeding and specifies the probable vascular origin. CT, hence, can be used as a controller for angiographic or surgical intervention. Though embolization has a high success rate, about $45 \%$ of patients necessitate surgical management to control bleeding. Surgical approaches can be sternotomy, standard thoracotomy or mini-thoracotomy.

\section{Recommendation}

Prompt diagnosis, aggressive resuscitation and early intervention are recommended for the management of IMA injury. Involvement of multidisciplinary team is also recommended for patients with IMA injury, especially once the IMA injury is accompanied by a severe shock.

\section{Conclusion}

Penetrating chest trauma with isolated IMA injury is a very rare cause of massive 
haemothorax and associated with high mortality. Careful consideration of urgent thoracotomy for the ideal patients is most important for the successful outcome. Isolated penetrating IMA injury can be managed by mini-thoracotomy with enhanced recovery; however, it is case specific and needs proper judgement.

\section{Disclosure}

There are no conflicts of interest, financial or otherwise to disclose.

\section{References}

[1] Curley, S.A., Demarest, G.B. and Hauswald, M. (1987) Pericardial Tamponade and Hemothorax after Penetrating Injury to the Internal Mammary Artery. The Journal of Trauma, 27, 957-958. https://doi.org/10.1097/00005373-198708000-00020

[2] Vinces, F.Y. (2005) Delayed Hemothorax and Pericardial Tamponade Secondary to Stab Wounds to the Internal Mammary Artery. European Journal of Trauma, 31, 274-277. https://doi.org/10.1007/s00068-005-1007-2

[3] Holt, P., Stone-Tolcher, K. and Franklin, I. (2005) An Unusual Cause of Tamponade. Scandinavian Journal of Trauma, Resuscitation and Emergency Medicine, 13, 236-238.

[4] Irgau, I., Fulda, G.J., Hailstone, D. and Tinkoff, G.H. (1995) Internal Mammary Artery Injury, Anterior Mediastinal Hematoma, and Cardiac Compromise after Blunt Chest Trauma. Journal of Trauma and Acute Care Surgery, 39, 1018-1021. https://doi.org/10.1097/00005373-199511000-00038

[5] Al Hassani, A., Abdul Rahman, Y., Kanbar, A., El-Menyar, A., Al-Aieb, A., Asim, M. and Latifi, R. (2012) Left Internal Mammary Artery Injury Requiring Resuscitative Thoracotomy: A Case Presentation and Review of the Literature. Case Reports in Surgery, 2012, Article ID: 459841. https://doi.org/10.1155/2012/459841

[6] Islam, S., Shah, J. and Singh, V.N. (2014) Emergency Thoracotomy-Isolated Internal Thoracic Artery Injury. Jurnalul de Chirurgie, 10, 171-173.

https://doi.org/10.7438/1584-9341-10-2-17 